\title{
In Situ Monitoring and Numerical Experiments on Vertical Deformation Profiles of Large-Scale Underground Caverns in Giant Hydropower Stations
}

\author{
Hao Wu $\mathbb{D}^{1,2}$ Jian Liu, ${ }^{3}$ Xiaogang Wang $\mathbb{D}^{1,2}$ Lipeng Liu $\mathbb{D}^{1,2}$ and Zhenhua Tian ${ }^{1,2}$ \\ ${ }^{1}$ State Key Laboratory of Simulation and Regulation of Water Cycle in River Basin, China Institution of Water Resources and \\ Hydropower Research, Beijing, China \\ ${ }^{2}$ Geotechnical Engineering Department, China Institution of Water Resources and Hydropower Research, Beijing, China \\ ${ }^{3}$ Yalong River Hydropower Development Company Limited, Chengdu, China
}

Correspondence should be addressed to Hao Wu; wuhao@iwhr.com

Received 8 December 2020; Revised 30 December 2020; Accepted 20 January 2021; Published 11 February 2021

Academic Editor: Bin Gong

Copyright $\odot 2021$ Hao Wu et al. This is an open access article distributed under the Creative Commons Attribution License, which permits unrestricted use, distribution, and reproduction in any medium, provided the original work is properly cited.

\begin{abstract}
Spatial response is a feature of rock deformation in regions surrounding large-scale underground caverns and includes significant vertical components due to the construction method of layered excavation. This vertical response is different to the longitudinal response of excavation deformation surrounding shallow tunnels. The study of longitudinal deformation profiles (LDPs), which describe the spatial response of longitudinal tunnel excavation and surrounding rock deformation, is a mature field. However, there has been no independent discussion of the relationship between vertical excavation and the spatial response of deformation in large-scale underground caverns nor the incremental characteristics of layered excavation. In this paper, we define the attenuation function $\lambda(x)$ of unloading strength based on theoretical analyses and numerical simulations. We also propose the concept and form of the vertical deformation profile (VDP) curve for the first time and apply it to the Baihetan and Lianghekou Hydropower Stations. After fitting the complete VDP curve with a Levenberg-Marquardt algorithm, we verify its validity by comparing predicted data with in situ monitoring data. The curve can be used to quantitatively analyze the relationship between layered excavation and incremental deformation of surrounding rock, providing a basis for the rapid evaluation of staged deformation during the excavation of large underground caverns. This study has practical significance for the control of deformation in rock surrounding excavations and decision-making during the construction progress.
\end{abstract}

\section{Introduction}

Nearly $80 \%$ of China's hydropower resources are concentrated in the southwest [1]. Landforms in this region have heavy rainfall, numerous mountains, and large drops, providing abundant hydropower resources along the Jinsha, Yalong, Dadu, and Lancang Rivers. At present, China is developing hydropower resources in the form of cascade reservoirs in this region. Indeed, a number of giant hydropower stations are already under construction, including Baihetan, Wudongde, Yangfanggou, Lianghekou, and Shuangjiangkou Hydropower Stations. Most of these projects have underground caverns that spanned more than $30 \mathrm{~m}$ and whose height exceeded $70 \mathrm{~m}$, which is considered a large-scale underground cavern, and the difficulty of construction and safety control is unprecedented; there has been wide concern about the stability of large-scale underground caverns.

Due to the complex geological conditions, large cavern size, blasting excavation, and other reasons, during the construction process of the underground caverns, large deformation occurred in some engineering, and even a variety of failure phenomena are encountered in some parts of the underground caverns, resulting in the delay of construction period, such as Baihetan [2], Houziyan [3], and Jinping I Hydropower Station [4].

The deformation response mechanism in these caverns is very complex. Influencing factors include the unloading effect caused by release of rock energy, the redistribution of 
surrounding rock stress caused by layered excavation, and the change of surrounding rock properties and boundary constraints. Many researchers have made in-depth analysis on specific engineering. For example, Wu et al. [5] have discussed the stability of underground powerhouse caverns of the Three Gorges project, Huang et al. [6] have generally analyzed the displacement magnitude and deformation rate of surrounding rock during the construction of Pubugou Hydropower Station's underground powerhouse, Yang et al. [7] analyze the surrounding rock deformation characteristic during the excavation of the upper part of the underground powerhouse of Houziyan hydropower station and predict the two-stage excavation in the future. Taking Xiluodu Hydropower Station as the research object, Li et al. [8] describe the safety control technology of underground caverns, and Li et al. [9] analyze the failure mechanism of the excavation damaged zones in Jinping I Hydropower Station and evolution assessment. The study of internal deformation mechanism reveals that the deformation of underground cavern includes two characteristics: time-dependent effects and spatial responses [10]. Time-dependent effects are a long-term process caused by stress redistribution of surrounding rock, and spatial responses are mainly a short-term process caused by cumulative blasting of layered excavation in large scale cavern.

In the study of rock deformation control, long-term monitoring deformation data are often used to construct prediction models. The common models include the regression analysis model [11], grey system model [12], neural network model [13], support vector machine model [14], and time series model [15]. This kind of analysis and prediction model is based on long-term safety monitoring data, and the model is mainly based on time-dependent effects. But in fact, in the process of super large cavern excavation, especially for rock mass with lithology integrity or hard block structures, the rock is affected by multiple vertical excavation accumulation, the excavation period is short, the weight of time-dependent effects is small, and the deformation characteristics are mainly spatial responses. The in situ monitoring data from Jinping I [16], Xiangjiaba [17], Xiluodu [8], Guandi [18], Houziyan [19], and Pubugou [6]. Hydropower Stations in China indicate that there is a significantly positive correlation between the deformation growth of surrounding rock and the vertical excavation depth of the working face. Generally speaking, the above models have the following disadvantages for deformation control: (1) they do not separate and identify the time-dependent and space effect superposition components in the deformation of surrounding rock; (2) it is difficult to predict the deformation of surrounding rock in different stages because of the poor applicability to layered excavation; and (3) technicians at the construction site need a simpler and easier-to-use evaluation method for the different stages of surrounding rock deformation.

In addition, according to engineering characteristics and excavation sequences, this spatial response can be roughly divided into longitudinal and vertical components. Research on the longitudinal spatial response has mainly focused on tunnel engineering, including the LDP curves that describe the longitudinal spatial response of tunnel wall deformation during excavation [20-23]. The study of LDP curves is still undergoing continuous optimization, but it is clear that they can describe the longitudinal spatial response of surrounding rock deformation during excavation of shallow tunnels. In contrast, there are few studies of the vertical spatial response to underground caverns.

In this paper, we qualitatively discuss the evolution characteristics of surrounding rock deformation in large-scale underground engineering projects by in situ monitoring data. Following the principles underlying the LDP curve, we firstly proposed the concept of the vertical deformation profile curve; the vertical spatial response mechanism of rock deformation control and face vertical excavation in large underground caverns is studied; we define the attenuation function $\lambda(x)$ of unloading strength and deduce the form of the VDP curve by FLAC ${ }^{3} \mathrm{D}$ numerical simulation. The validity of this VDP curve is tested by using in situ monitoring data of two engineering projects and the physical meaning of key parameters in the VDP curve explained. Because these physical explanations are clear, the VDP curve is suitable for the evaluation of phased deformation of large-scale underground caverns.

\section{On-Site Monitoring of Surrounding Rock Deformation Pattern}

2.1. Excavation Sequences of Large-Scale Underground Caverns. Compared with shallow tunnels, the underground caverns of hydropower stations have large-scale, high in situ stress and complex geological characteristics. These constraints mean that large-scale underground caverns cannot be excavated in full cross section. Therefore, large-scale underground caverns are excavated in layers during hydropower construction. Table 1 summarizes the data from representative underground powerhouses in Southwest China, ranging from 65.38 to $89.80 \mathrm{~m}$ high and excavated in 8-12 layers. Figure 1 shows the layered model of the underground powerhouse of Baihetan Hydropower Station. Serial numbers I-X represent the excavation layers of the cavern; the height of each excavation layer is between 2.7 and $13.6 \mathrm{~m}$. A typical construction method is to excavate the two sides of the top arch in blocks following removal of the pilot tunnel. After this top arch is formed, the side walls on both sides are excavated and supported layer by layer.

\subsection{Monitoring Method of Surrounding Rock Deformation.} The purpose of deformation monitoring is to evaluate the stability of underground caverns and provide valuable data for dynamic adjustment of the construction process, support design, analysis, and predictions. In situ monitoring data contains all the intrinsic information underlying deformation evolution of surrounding rock and is the most intuitive external reflection of surrounding rock deformation.

The main observation and monitoring methods for surrounding rock deformation include internal space convergence, multipoint extensometers, and sliding micrometers. Of these, multipoint extensometers are the most effective and widely used and contain either vibrating string or differential resistance sensors. As shown in Figure 2, the operating 
TABLE 1: Statistics of representative hydropower station underground powerhouses in Southwest China.

\begin{tabular}{lccc}
\hline Hydropower station & Height of major powerhouse $(\mathrm{m})$ & Vertical buried depth $(\mathrm{m})$ & Number of layered excavations \\
\hline Jinping I Hydropower Station & 68.80 & $160 \sim 420$ & 11 \\
Jinping II Hydropower Station & 72.20 & $231 \sim 327$ & 8 \\
Xiluodu Hydropower Station & 75.10 & $340 \sim 480$ & 10 \\
Houziyan Hydropower Station & 68.70 & $400 \sim 660$ & 9 \\
Dagangshan Hydropower Station & 74.60 & $390 \sim 520$ & 10 \\
Guandi Hydropower Station & 78.00 & $154 \sim 427$ & 11 \\
Xiaowan Hydropower Station & 79.38 & $380 \sim 480$ & 10 \\
Baihetan Hydropower Station & 88.70 & $260 \sim 330$ & 10 \\
Wudongde Hydropower Station & 89.80 & $220 \sim 380$ & 11 \\
Ertan Hydropower Station & 65.38 & $250 \sim 350$ & 12 \\
Xiangjiaba Hydropower Station & 85.50 & $105 \sim 225$ & 9 \\
Nuozhadu Hydropower Station & 77.77 & $180 \sim 220$ & 10 \\
Shuangjiangkou Hydropower Station & 67.32 & $321 \sim 498$ & 10 \\
Yangfanggou Hydropower Station & 75.57 & $200 \sim 330$ & 9 \\
Changheba Hydropower Station & 73.35 & $285 \sim 480$ & 10 \\
Lianghekou Hydropower Station & 66.80 & $400 \sim 450$ & 9 \\
\hline
\end{tabular}

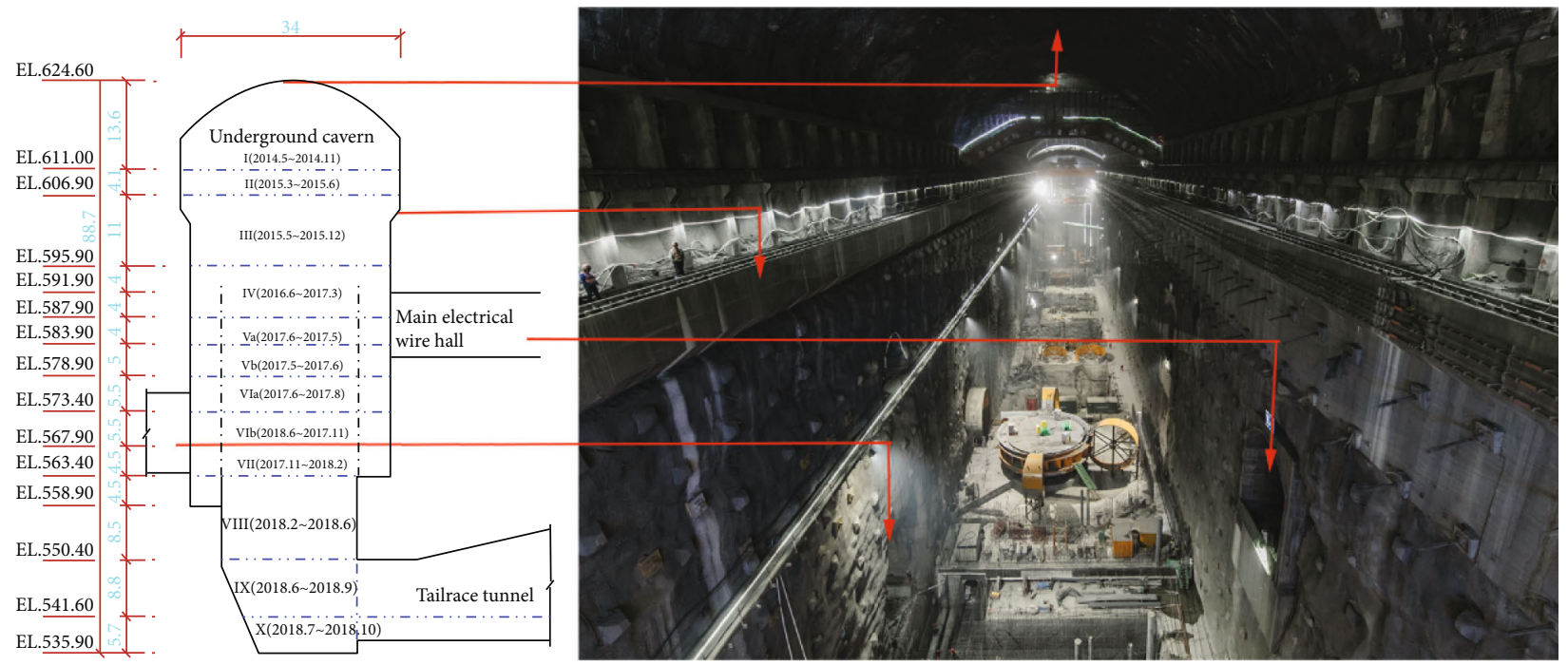

Figure 1: Schematic diagram of the layered excavation of large-scale underground caverns (Baihetan Hydropower Station).

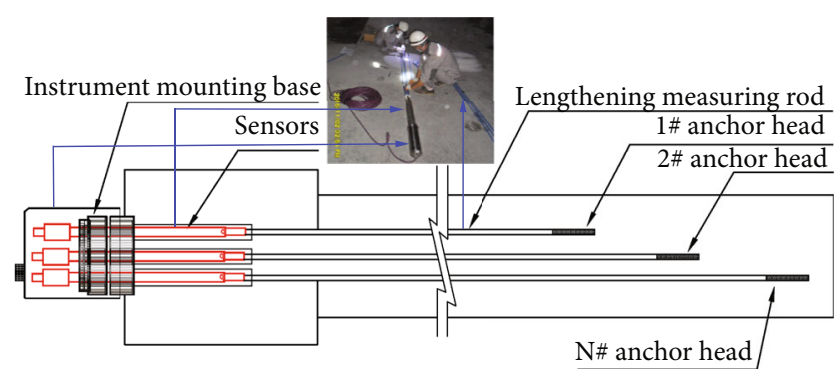

FIgUre 2: Multipoint displacement meter structural diagram (left) and on-site installation (right).

principle of multipoint extensometers is to install a set of instruments in the borehole of surrounding rock and arrange measuring heads at different depths to monitor displace- ment. There are two types of installation: direct-installed and preinstalled. Direct-installed is the most common method, in which the instrument is directly installed in the powerhouse as the working face passes through the desired monitoring point. The deepest anchor head is assumed to be the fixed point ( $N \#$ in Figure 2).

2.3. Deformation Characteristics of Surrounding Rock. After excavation of the cavern, deformation of surrounding rock tends to develop towards the free face, but the deformation process and trend can differ due to control of the main stress and occurrence of the geological structural plane. The development trend of surrounding rock deformation is therefore monitored consistently, including specific phenomena. In this section, we focus on the characteristics of consistency and explain two kinds of specific phenomena. 


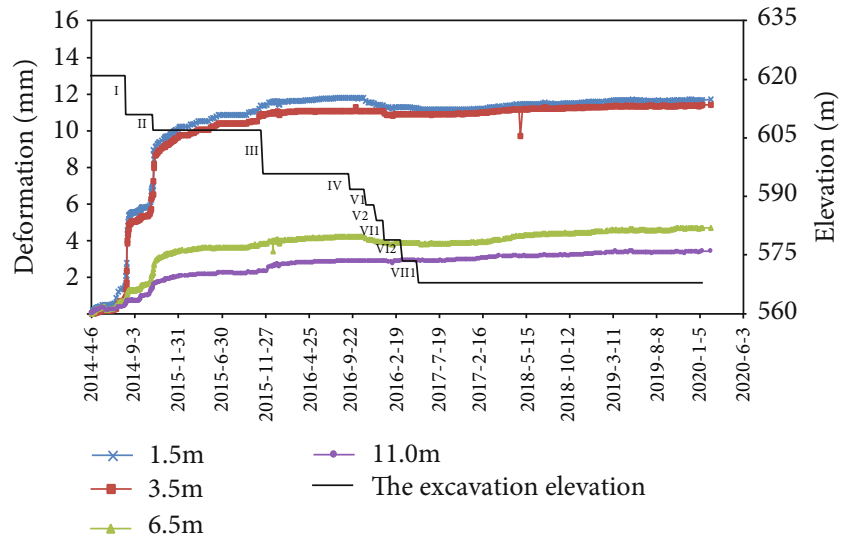

(a) Typical in situ monitoring data from Baihetan

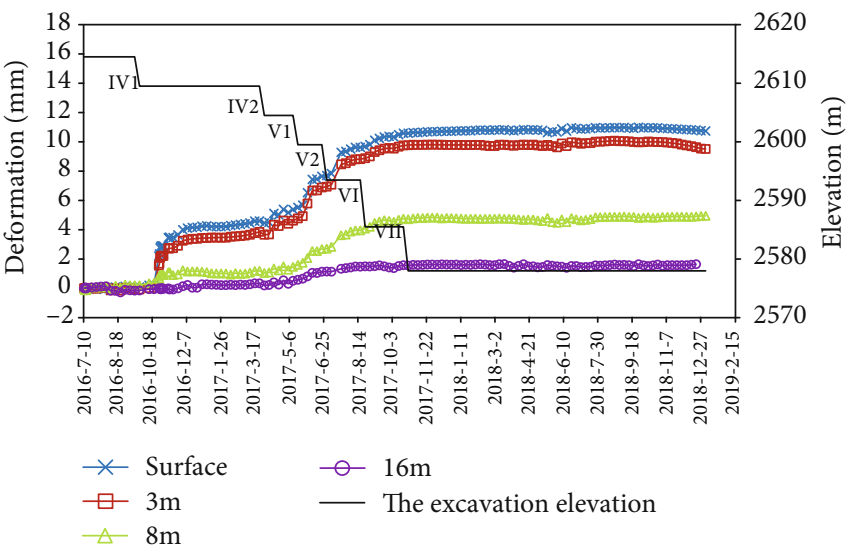

(c) Typical in situ monitoring data from Lianghekou

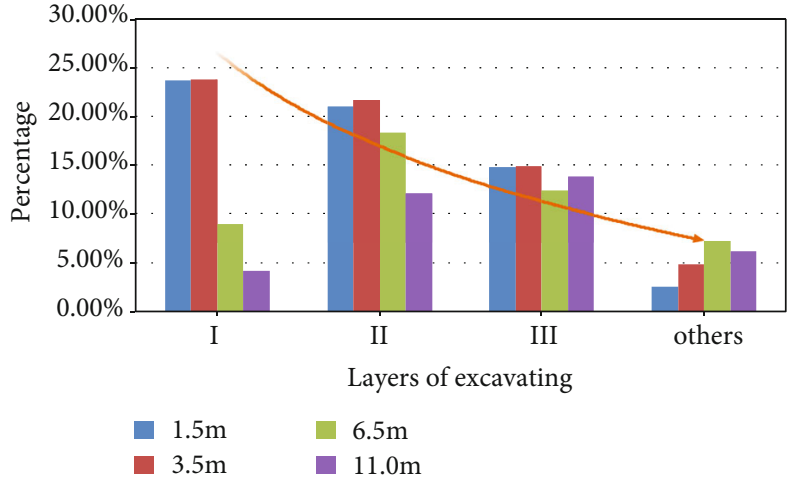

(b) Percentage of deformation caused by excavation of each layer

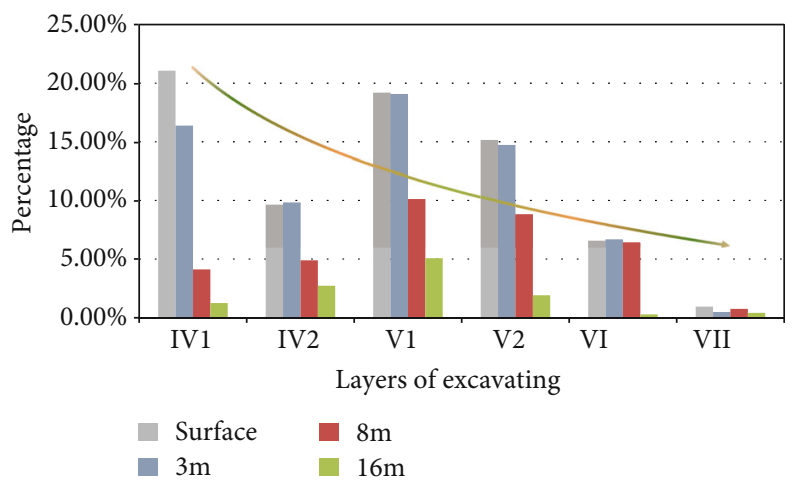

(d) Percentage of deformation caused by excavation of each layer

Figure 3: Time-displacement curves for typical surrounding rock deformation measuring points.

Figure 3 shows the in situ monitoring data from two typical engineering projects that were observed by our research group. These data show a strong correlation between displacement and the excavation sequence. The monitored displacement at different depths grows synchronously and gradually accumulates from the inside to the outside of the rock mass. The development of displacement can be divided into two stages: sudden growth in response to excavation and gradual convergence after the working face moves far away. The in situ monitoring data from Jinping I, Xiangjiaba, Xiluodu, and Guandi Hydropower Stations [6, 8, 16-19] illustrate this point of view. The main deformation characteristic of rock mass is that of high integrity with few fissures or faults, but when a fault or fracture zone passes through the deformation monitoring area of rock mass, two other characteristics become apparent. It can be seen from Figures 3(b) and $3(\mathrm{~d})$ that displacement of the monitoring point caused by excavation of each layer decreases step by step.

From the perspective of spatial distribution, deformation of surrounding rock in some parts varies with depth. Hibino and Motojima [24] suggested that deformation surrounding large underground caverns can be divided into strain deformation and fracture deformation. As shown in Figure 3(a), the displacement growth process at a depth of

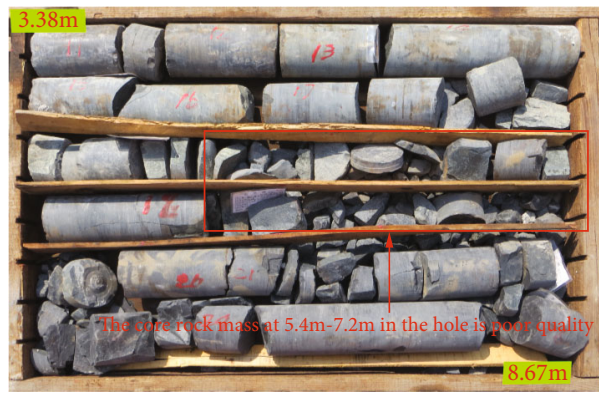

FIgURE 4: Site core image.

$1.5 \mathrm{~m}$ and $3.5 \mathrm{~m}$ from the free face is synchronous, and therefore, displacement within this range is mainly due to strain deformation. It can also be seen from photos of in situ core samples that the rock has crumbled and broken into pieces at a depth range of 5.4-7.2 $\mathrm{m}$ from the free face (Figure 4). On either side of this crushed core area, the rock is relatively complete and has maintained columnar form. Therefore, displacement between 3.5 and $6.5 \mathrm{~m}$ is mainly due to fracture deformation, which indicates that the fracture expands during the process of unloading stress adjustment. 


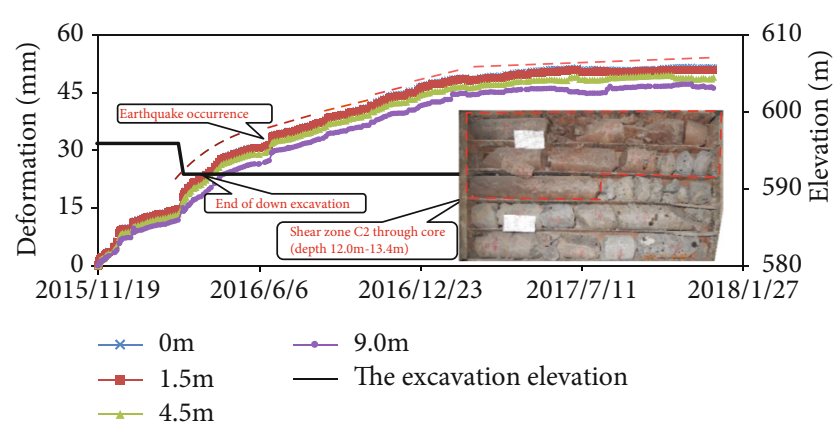

FIGURE 5: Time-displacement curve of surrounding rock affected by weak interlayer.

Due to soft plasticity at rock fault zones, strain energy is released gradually and slowly according to rock rheology, and the resulting time-dependent characteristics of deformation are obvious (Figure 5).

On the contrary, deformation of the rock mass with high integrity and less fissures or faults shows no obvious timedependent characteristics; therefore, deformation converges soon after excavation. According to the statistics of in situ monitoring data from multiple engineering projects, rheology deformation of this kind of rock is generally less than $5 \%$ of total deformation and can therefore be neglected. For this reason, rock mass with high integrity and less fissures or faults is the subject of the spatial response of surrounding rock deformation studied in this paper.

To summarize the above description of the step-shaped curve of surrounding rock deformation, the general characteristics of vertical spatial responses can be described when large-scale underground caverns are excavated in layers. The induced surrounding rock deformation develops in a stepped way with the elevation of the working face lowering in stages. Deformation growth is the largest at the initial stage and decreases as soon as the face passes the section of interest, resulting in a vertical spatial effect of the excavation face. The above process is a vertical spatial response of cavern excavation.

\section{Numerical Experiments}

3.1. Overview of Model. Research on the quantitative relationship between layered excavation steps and incremental surrounding rock deformation has been debated for a long time. For the elastic-plastic deformation $\delta_{\mathrm{e}}$ caused by excavation unloading of rock mass, Zhu et al. [25] obtained a predictive formula for $\delta_{\mathrm{e}}$ at a key point of the high side wall of surrounding rock using regression analysis of a large number of practical engineering data and theoretical calculations.

$$
\delta_{\mathrm{e}}=\eta h\left[a\left(\frac{1000 \lambda \gamma H}{E}\right)^{2}+b\left(\frac{1000 \lambda \gamma H}{E}\right)+c\right] \cdot 10^{-3}
$$

In formula (1), $h$ is the excavation height of the underground powerhouse; $\lambda$ is the lateral pressure coefficient of initial in situ stress; $\gamma$ is the bulk density of rock mass; $H$ is the burial

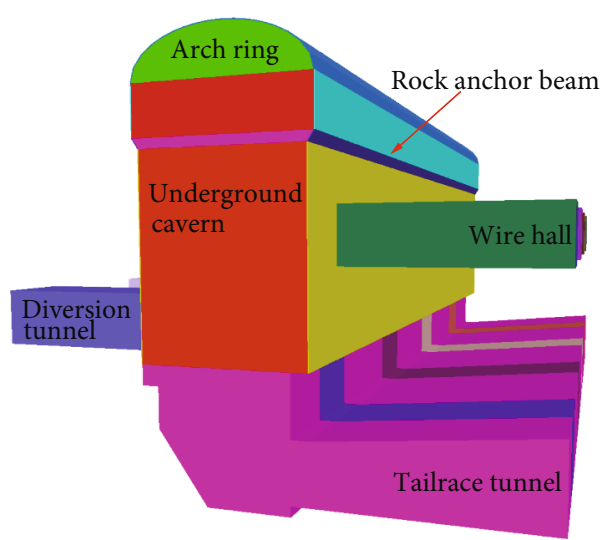

Figure 6: Three-dimensional model of the underground cavern.

depth of the cavern; $E$ is the deformation modulus of rock mass; $a, b$, and $c$ are empirical parameters that are related to the engineering design layout and rock mass characteristics.

According to formula (1), when being buried deep, in situ stress, and rock character are determined, there is a notable positive correlation between $\delta_{\mathrm{e}}$ and the excavation height of the powerhouse. Furthermore, there is an approximate linear relationship between $\delta_{\mathrm{e}}$ and the elevation of the working face $h_{\mathrm{EL}}$, to form the excavation unloading deformation $\delta_{\mathrm{e}}^{\prime}$, as follows:

$$
\delta_{\mathrm{e}}^{\prime}=A\left(h_{0}-h_{\mathrm{EL}}\right)
$$

In formula (2), $h_{0}$ is the elevation of the monitoring point in the rock and $A$ is an undetermined coefficient. In largescale underground caverns, the case of $h_{\mathrm{EL}} \leq h_{0}$ is the most relevant.

However, this simple linear formula does not take into account the vertical spatial response caused by advancement of the working face and cannot reflect the step-shaped characteristics of displacement. Therefore, this formula does not apply to the case of large-scale underground excavation in layers. Using Baihetan Hydropower Station as a prototype, we created a fully three-dimensional finite difference model using FLAC ${ }^{3 D}$ software with the purpose of simulating layered excavations of large-scale underground caverns in different rock masses. These simulations were able to explore the quantitative relationship between drilling height and rock displacement under different conditions. In order to render the vertical spatial response unaffected by other factors, the rheology simulation function of the software was closed in the numerical calculation so that the influence of long, large crevices including weak interlayers could be avoided in the model.

According to the characteristics of in situ stress in Southwest China, the simulated initial in situ stress field is dominated by structural horizontal stress, the lithology is mainly class II and III rock mass, and the influencing part of the geological structural plane is class IV rock mass. $\Sigma_{1}$ is between 19 and $23 \mathrm{MPa}, \sigma_{2}$ is between 13 and $16 \mathrm{MPa}$, and $\sigma_{3}$ is between 8 and $12 \mathrm{MPa}$. The excavation scheme used for the simulation was layered 
TABLe 2: Physical and mechanical parameters of surrounding rock and concrete shotcrete.

\begin{tabular}{lcccccc}
\hline Rock quality/constitutive relationship & $\begin{array}{c}\text { Bulk modulus } \\
(\mathrm{GPa})\end{array}$ & $\begin{array}{c}\text { Shear modulus } \\
(\mathrm{GPa})\end{array}$ & $\begin{array}{c}c \\
(\mathrm{MPa})\end{array}$ & $\begin{array}{c}\text { Tensile strength } \\
(\mathrm{MPa})\end{array}$ & $\begin{array}{c}\text { Dip of joint } \\
\left({ }^{\circ}\right)\end{array}$ & $\begin{array}{c}\text { Joint } f \\
\text { II/mohr }\end{array}$ \\
III/ub (with gentle fissure) & 16.6 & 12.5 & 1.48 & 2.51 & 3.51 & $/$ \\
III/ub (with steep fissure) & 12.3 & 7.4 & 1.11 & $1 . .86$ & 1.22 & 20 \\
Concrete spraying layer/elas & 25.0 & 7.4 & 1.11 & 1.86 & 0.86 & 70 \\
\hline
\end{tabular}

mohr: Mohr Coulomb model; elas: isotropic elastic model; ub: ubiquitous joint model.
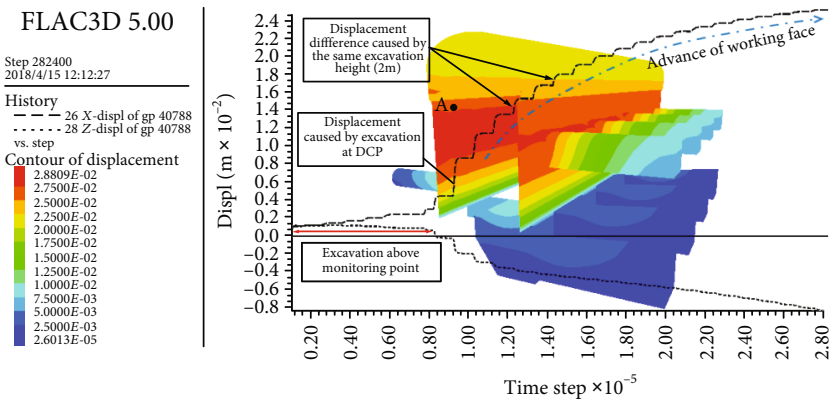

(a) Calculated step-displacement curves for typical

measuring points (class II isotropic surrounding rock)
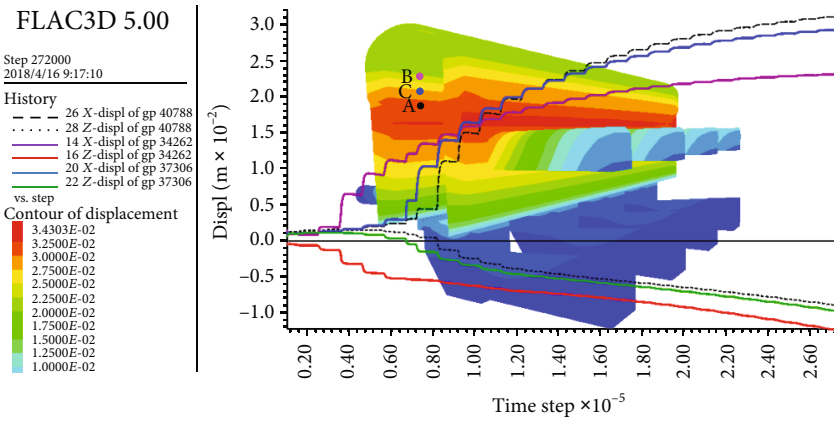

(c) Calculated step-displacement curves for typical measuring points (surrounding rock excavation with gentle dip fissure surfaces and timely support)
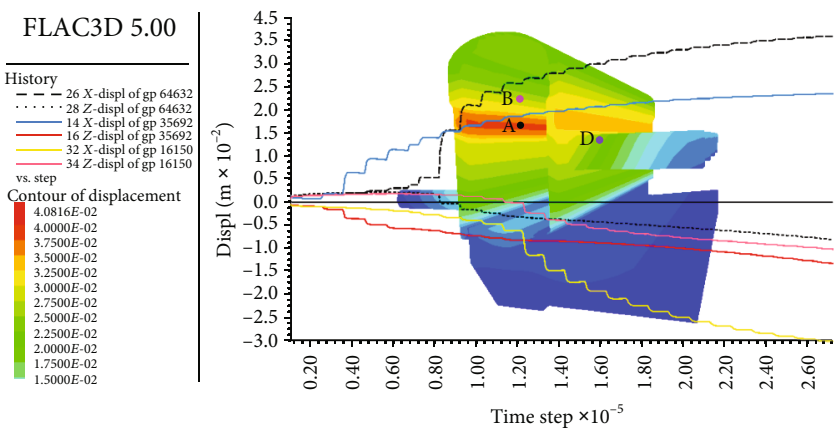

(e) Calculated step-displacement curves for typical measuring points (surrounding rock excavation with weak interlayer and timely support)

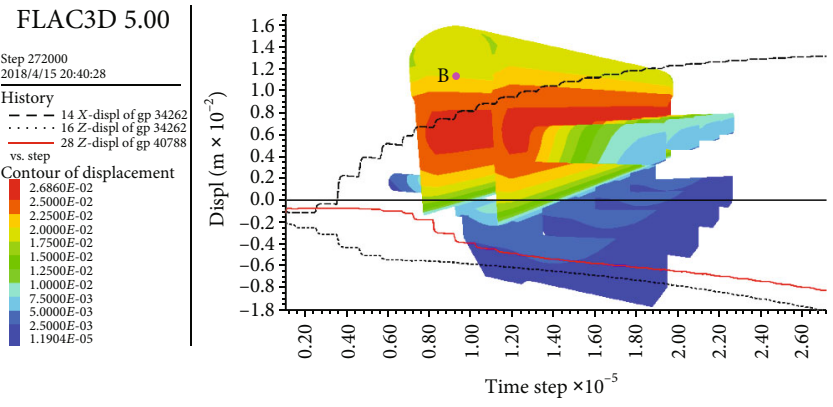

(b) Calculated step-displacement curves for typical measuring points (isotropic surrounding rock excavation and timely support)
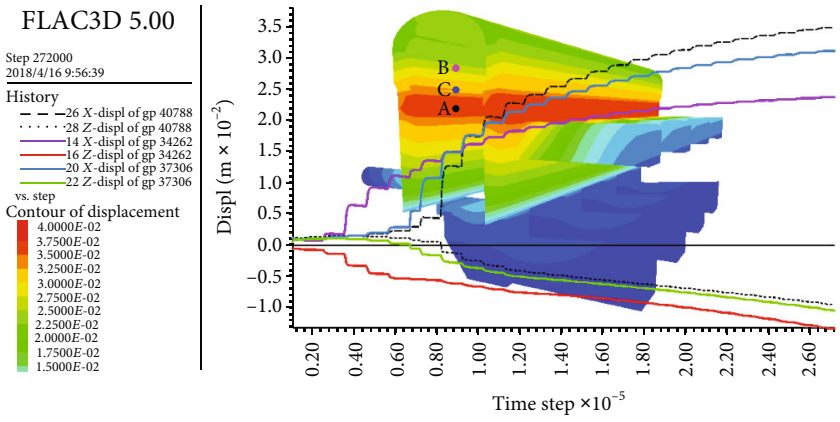

(d) Calculated step-displacement curves for typical measuring points (surrounding rock excavation with steep dip fissure surfaces and timely support)

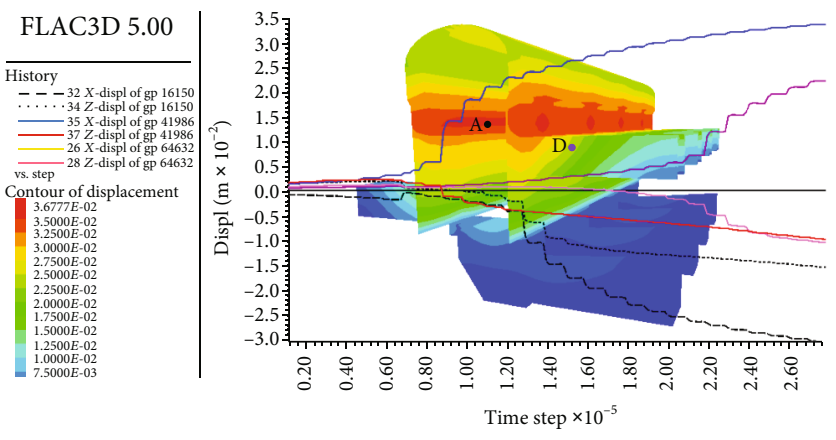

(f) Calculated step-displacement curves for typical measuring points (surrounding rock of the cross cavern)

FIGURE 7: Numerical simulation results of representative monitoring points.

excavation with shotcreting and bolt follow-up supports. The structural size of the finite difference model, shown in Figure 6, was $30.0 \mathrm{~m}(27.0 \mathrm{~m}$ below the rock anchor beam) $\times 80.0 \mathrm{~m} \times 280.0 \mathrm{~m}$. Rock mass parameters are listed in Table 2 .
3.2. Analysis of Numerical Simulation Results. Figures 7(a)$7(f)$ show the displacement field formed by excavation under different conditions and step-displacement graphs for typical monitoring points. These figures show the displacement patterns of the same monitoring point under different rock and 


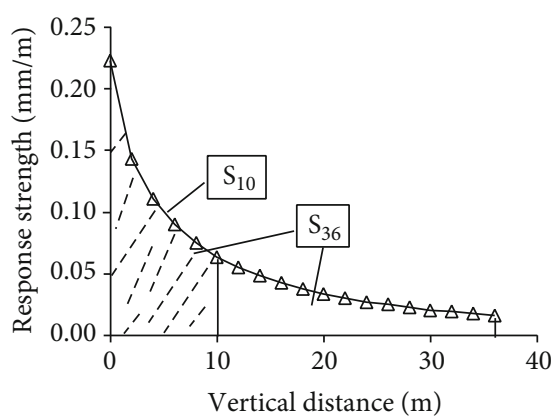

(a) Type II homogeneous rock

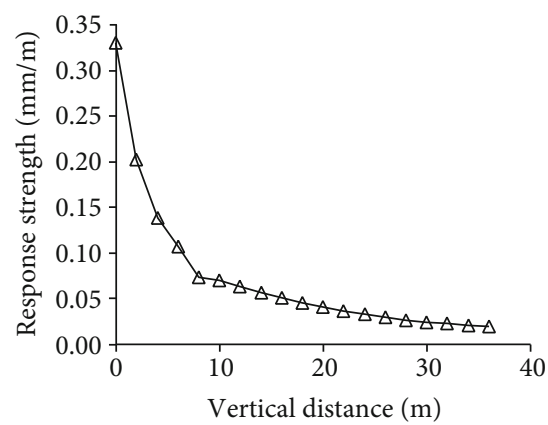

(c) Rock with gentle fissure

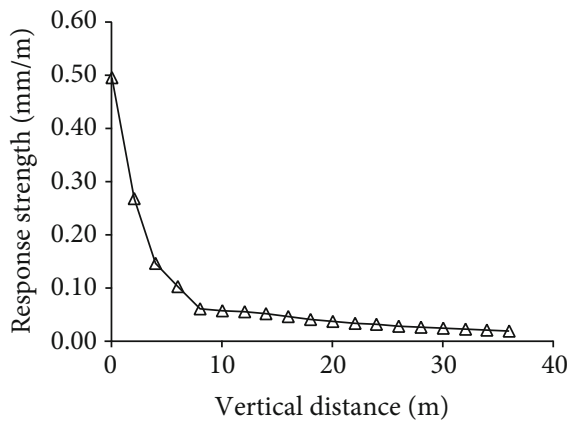

(e) Rock with soft interlayer

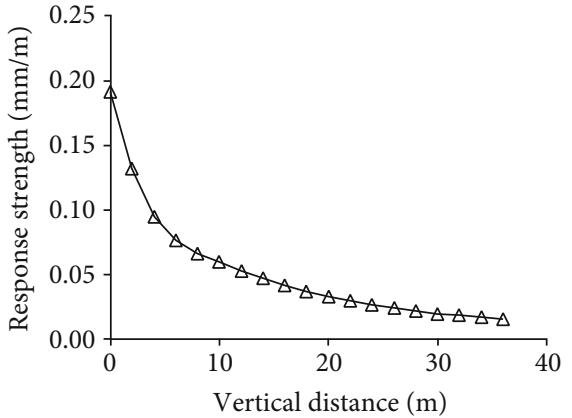

(b) Type II homogeneous rock with support fissure

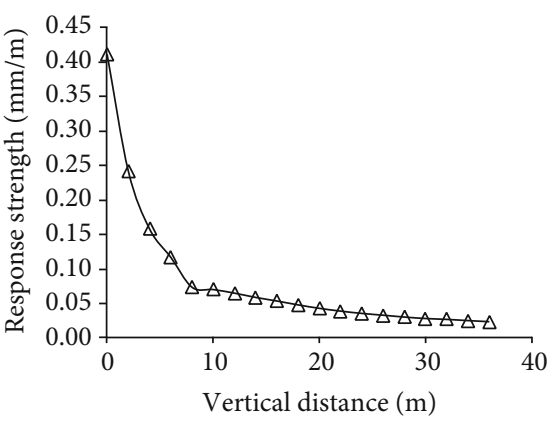

(d) Rock with steep fissure

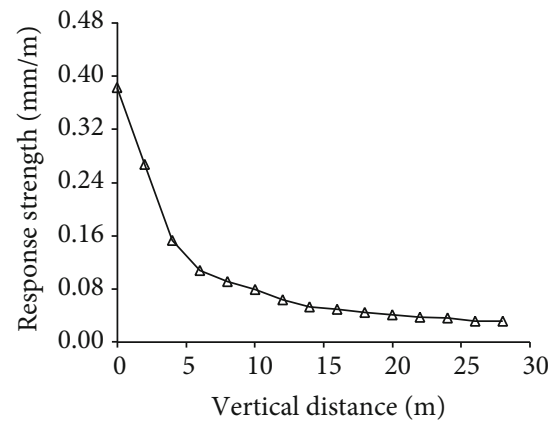

(f) Rock at intersection

FIGURE 8: Distance-response intensity curves representing vertical distance of the working face versus unloading response.

support conditions and the displacement patterns of different points under the same rock and support conditions. The simulations show that the displacement of surrounding rock increases in a gradual stepped form when the cavern is excavated layer by layer. This is consistent with in situ monitoring data from practical engineering. Taking excavation in class II homogeneous surrounding rock as an example, when the monitoring point and working face are at the same elevation, we define the monitoring point as the direct constraint point (DCP). The displacement increment caused by excavation of surrounding rock at the DCP is the largest, accounting for about $12-16 \%$ of the total displacement. Following that, a sudden displacement increase occurs with each layer of excavation, and increments of displacement gradually decrease as the working face moves away from the monitoring point. Compared to the arch ring and upper side wall, the vertical spatial response and the unloading effect of the rock anchor beam and its lower wall rock are stronger and the displacement is larger, which is consistent with the in situ monitoring data. Under different rock and support conditions, the dis- placement growth pattern of surrounding rock deformation is essentially the same, but the magnitude of deformation is different.

In Figure 7, different representative monitoring points are distinguished by color. Monitoring point A is located at the lower side wall of the upstream side rock anchor beam; monitoring point $\mathrm{B}$ is located at the upper side wall of the upstream side rock anchor beam; monitoring point $\mathrm{C}$ is located at the upstream side rock anchor beam; monitoring point $\mathrm{D}$ is located at the intersection of the powerhouse and the main electrical wire hall; monitoring point $\mathrm{E}$ is located at the intersection of the powerhouse and the tailrace tunnel.

3.3. Form of the VDP Curve. Based on the above description, the excavation unloading response strength $\Lambda(\mathrm{mm} / \mathrm{m})$ is defined by

$$
\Lambda=\frac{\Delta \delta}{\Delta h},
$$




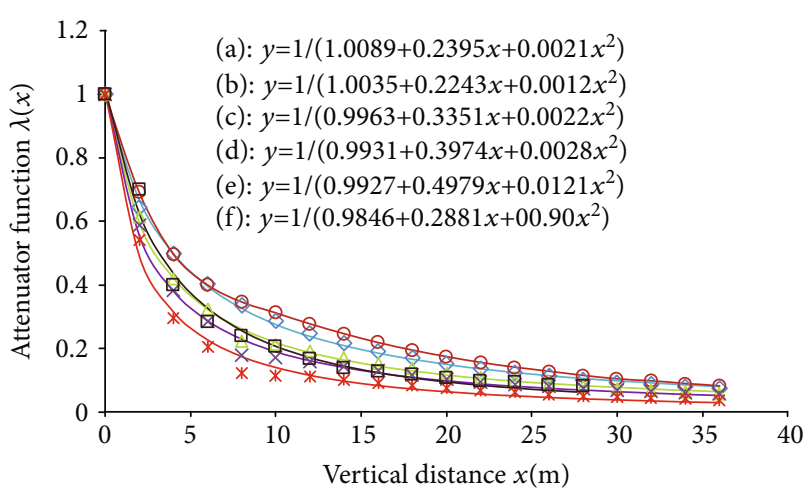

$\diamond$ (a)II type homogeneous rock

o (b)II type homogeneous rock with support

$\Delta$ (c)Rock with gentle fissure

$\times$ (d)Rock with steep fissure

* (e)Rock with soft interlayer

․ (f)Rock at intersection

FIgURE 9: The attenuation function $\lambda(x)$ of the vertical spatial response of unloading deformation.

where $\Delta h$ is the height of each excavation layer and $\Delta \delta$ is displacement increment of surrounding rock caused by $\Delta h$ of working face advancing vertically. Therefore, $\Lambda$ represents the displacement increment of monitoring points caused by vertical excavation per meter.

Figure 8 shows attenuation curves of the response strength of typical monitoring points versus the increase in vertical distance between the working face and different positions outputted by the FLAC ${ }^{3 \mathrm{D}}$ finite difference model. Taking the $36 \mathrm{~m}$ excavation of a typical monitoring point as an example, the accumulated deformation $S_{10}$ (the shadow area in Figure 8(a)) is about $65-85 \%$ of the total displacement $S_{36}$. In addition, comparative analysis reveals that $\Lambda$ becomes larger as surrounding rock properties worsen for the same excavation conditions, in agreement with common understanding.

The attenuation function $\lambda(x)$ of the vertical spatial response of unloading deformation is defined as

$$
\lambda(x)=\frac{\Lambda_{x}}{\Lambda_{0}}
$$

where $\Lambda_{0}$ is response strength when the monitoring point is $0 \mathrm{~m}$ away from the working face (i.e., when the monitoring point is the DCP) and $\Lambda_{x}$ is response strength when the monitoring point is $x \mathrm{~m}$ away from the working face. According to this definition, the attenuation function shown in Figure 9 can be drawn and fitted by the least squares method. $\lambda(x)$ can be expressed by

$$
\lambda(x)=\frac{1}{1+B \cdot x+C \cdot x^{2}} .
$$

In formula (5), $B$ and $C$ fitting parameters are obtained from the in situ monitoring data from excavations or initial excavations of the engineering test cross section.
According to the above analysis, we can multiply the excavation unloading deformation $\delta_{\mathrm{e}}^{\prime}$ in formula (2) with the attenuation function $\lambda(x)$ to obtain the deformation function $\delta_{\mathrm{e}}$ of the vertical distance effect of the working face, namely, the VDP curve:

$$
\delta_{\mathrm{e}}=\delta_{\mathrm{e}}^{\prime} \cdot \lambda(x)=\frac{A\left(h-h_{0}\right)}{1+B \cdot\left(h-h_{0}\right)+C \cdot\left(h-h_{0}\right)^{2}} .
$$

\section{Analysis and Verification of the VDP Curve}

4.1. The Method of VDP Curve Fitting. Following mathematical determination of the VDP curve, the unknown parameters $(A, B, C)$ need to be solved for subsequent use in engineering. A statistical learning method is a significant way to identify the parameters [26-29], and the essence of parameter solution in the VDP curve is a nonlinear least squares problem that can be solved by the common Levenberg-Marquardt (L-M) algorithm. [30-38] The core idea of this solution is to linearize the nonlinear function, then imitate the least squares method for this linear function. The solution process is as follows.

There is a question raised: for the function $x=f(P)$, given $f(\cdot)$ and the monitoring data vector $x$ containing noise, estimate $P$.

Step 1. Take the initial point $p_{0}$ and termination control constant $\varepsilon$ to make a function containing $\varepsilon_{0}$ (see formula (7)). The factors $K, \lambda_{0}$, and $V$ in the L-M algorithm are $0,10^{-3}$, and 10 , respectively.

$$
\varepsilon_{0}=\left\|x-f\left(p_{0}\right)\right\|
$$

Step 2. Calculate the Jacobi matrix $J_{k}$, and construct the incremental equation

$$
\begin{gathered}
\overline{N_{k}} \cdot \delta_{k}=J_{k}^{T} \varepsilon_{k}, \\
\overline{N_{k}}=J_{k}^{T} J_{k}+\lambda_{k} I .
\end{gathered}
$$

Step 3. $\delta_{k}$ is obtained by solving the incremental equation.

(1) If equation (9) holds, Loop (1) is executed

$$
\left\|x-f\left(p_{k}+\delta_{k}\right)\right\|<\varepsilon_{k}
$$

Loop (1):

Let $p_{k+1}=p_{k}+\delta_{k}$, if $\left\|\delta_{k}\right\|<\varepsilon$; then stop iteration and output result; otherwise, $\lambda_{k+1}=\lambda_{k} / v$ go back to Step 2

(2) If equation (10) holds, Loop (2) is executed

$$
\left\|x-f\left(p_{k}+\delta_{k}\right)\right\| \geq \varepsilon_{k}
$$

Loop (2):

Let $\lambda_{k+1}=\lambda_{k} \cdot v, \delta_{k}$ is obtained by solving the incremental again and go back to Step 1 


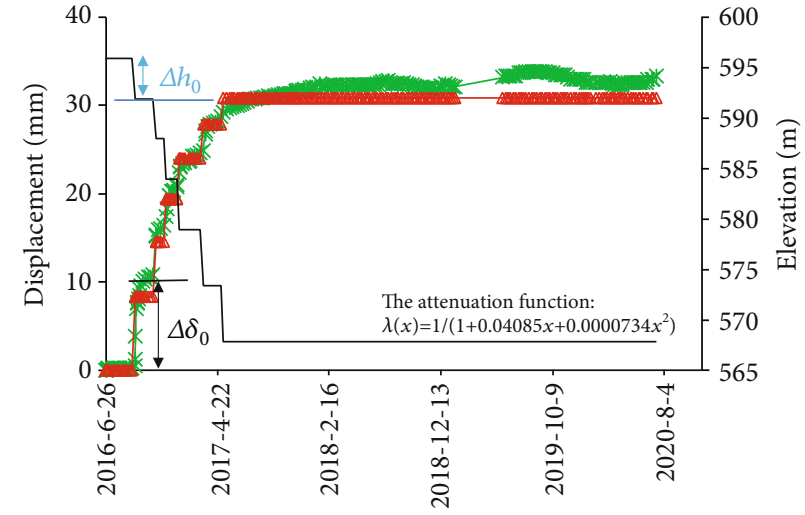

(a) Upstream side wall EL.593 m (left bank of Baihetan)

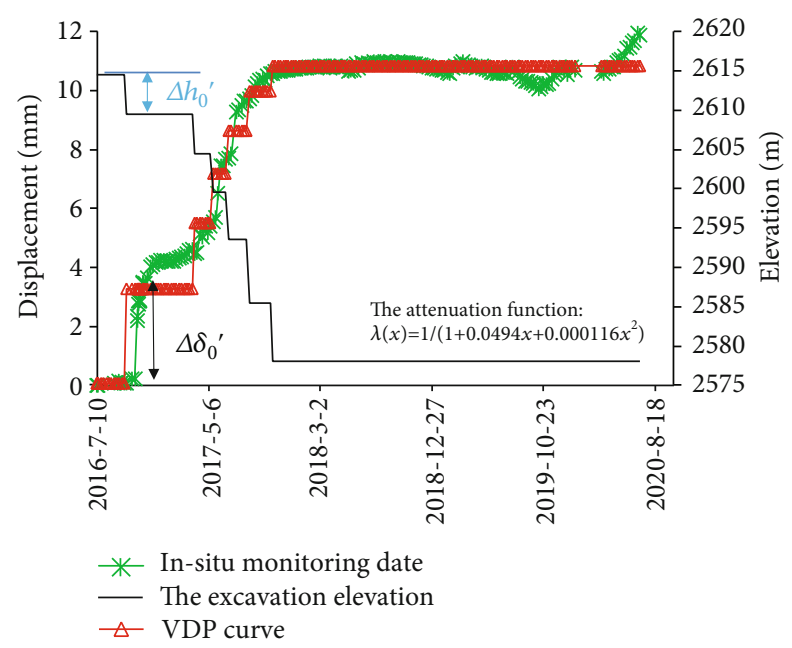

(c) Downstream side wall EL.2621 m (right bank of Lianghekou)

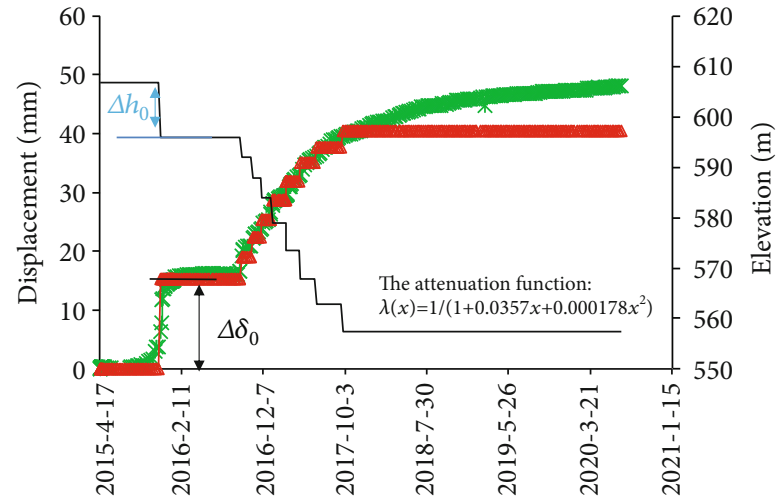

(b) Downstream side wall EL.605 m (left bank of Baihetan)

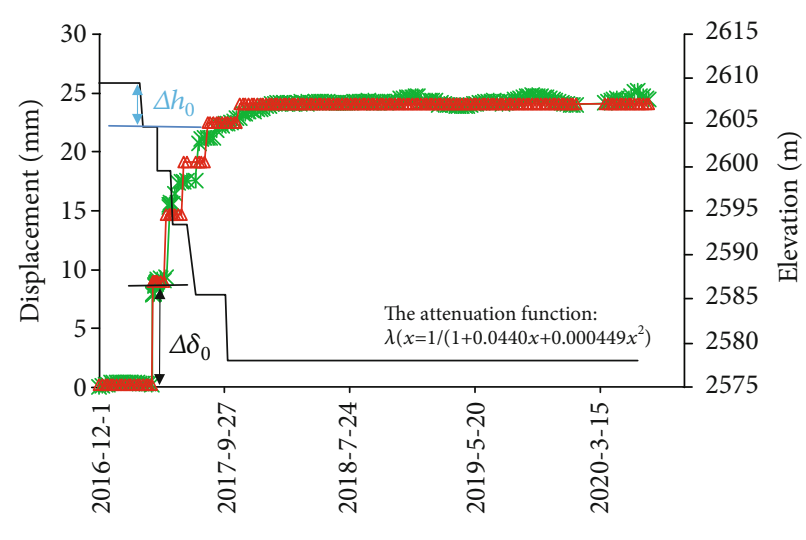

(d) Downstream side wall EL.2612 m (right bank of Lianghekou)

Figure 10: Verification of VDP curve calculation results and in situ monitoring data.

Execute continuous iteration, until the requirement of the termination control constant is met.

\subsection{Verification of the VDP Curve}

4.2.1. Accuracy of Deformation Prediction. In order to evaluate the applicability of the VDP formula for the prediction of surrounding rock deformation in practical engineering, 12 typical monitoring points (10 points from Baihetan Hydropower Station and 2 points from Lianghekou Hydropower Station) were selected for analysis and verification. These monitoring points were selected according to the following principles:

(1) There is a presence of a complete in situ monitoring data for deformation and excavation information of surrounding rock

(2) In preliminary analyses, deformation of surrounding rock was dominated by the vertical excavation spatial response and the rock mass was of good quality

Figure 10 shows the comparison between the in situ monitoring data for representative monitoring points and calculated data from the VDP curve. This VDP was obtained by using the monitoring data training model for the first 3-4 layers of excavation and VDP curve predictions for subsequent data. The VDP curve accurately reflects the relationship between excavation depth for each layer and the deformation increment. The correlation coefficient $R^{2}$ between the VDP calculation results for 12 measuring points and the measured data for surrounding rock deformation is 0.89-0.98.

It is clear from Figures 10(c) and 10(d) that the VDP curve may not be consistent with the displacement growth. The reasons for this phenomenon are analyzed from the point of view of engineering practice and the mechanism of VDP curve construction, and include the following three aspects:

(1) Because the excavation duration of some layers is long and the excavation process line takes the end of excavation as the time point for the stratification height to drop, there is a time difference between the excavation height and the deformation increment even though the surrounding rock deformation accumulates continuously during this period 
(2) The starting point of the VDP curve is the DCP mentioned above, but in practical engineering, the monitoring instrument is usually installed near the working face and a small part of the initial deformation is not monitored

(3) The VDP curve does not consider creep and other time-dependent characteristics. If the excavation stagnation time is too long (e.g., during construction of rock anchor beams), the time-dependent deformation of weak rock will be superimposed

These three factors cause the step difference between the VDP fitting line and monitoring curve, but they will not affect the value of using the VDP curve for the evaluation of surrounding rock deformation caused by single layer excavation.

The further study of the VDP curve parameters reveals that $A$ in formula (6) has a clear physical meaning, i.e., $A=$ $\Lambda_{0}$, which is the excavation unloading response strength when the vertical distance between the working face and monitoring point is $0 \mathrm{~m}$. In the actual calculation, the deformation increment $\Delta \delta_{0}$ caused by excavation of the surrounding rock at the DCP can be divided by the excavation layer height $\Delta h_{0}$.

4.3. Application Scenario. To summarize, the VDP curve can be constructed based on the spatial response of surrounding rocks and in situ monitoring data. In practical engineering, the VDP curve can be used to forecast and control the excavation deformation of each layer during layered excavation, providing a simple method for on-site technicians to quickly assess the deformation of surrounding rock and dynamically adjust the construction progress and support method.

The application of VDP to engineering proceeds as follows:

Step 1. When an underground chamber has excavation test conditions, representative surrounding rocks are selected for testing to obtain deformation data at direct restraint points and 2-3 layers of downward excavations. When excavation test conditions are not available, typical section monitoring data are collected for initial excavation.

Step 2. Based on the initial deformation data obtained in Step 1 , VDP curves for different rock mass properties in the project are fitted by the L-M algorithm.

Step 3. According to the VDP curves, deformation control indexes of different areas of the caverns are calculated by dividing the excavation surface elevation and rock mass properties.

Step 4. Engineers and technicians use deformation control indexes to evaluate the deformation of surrounding rock for each excavation layer. The newly obtained deformation data is returned to Step 2 and the VDP curve iterated to dynamically and precisely adjust the control index.
The VDP curve is effective for predicting excavation deformation of rock mass with high integrity and few fissures or faults. In rock mass with poor quality, the orientation of discontinuities plays an important role and the timedependent effect of deformation is considerable. For example, if the excavation stoppage time for a certain layer is long or in the time period after completion of excavation, the growth of surrounding rock deformation is mainly related to the time effect. It is clear from Figure 10 that there is a large difference between the observation value and the VDP calculation value due to this time-dependent effect. The spatial response component of deformation can be separated using calculation results from the VDP curve and the timedependent effect studied in isolation.

\section{Conclusion}

In this paper, in order to predict and control the deformation of surrounding rock during the construction period, we have analyzed the relationship between layered excavation of large-scale underground caverns and the deformation growth of surrounding rock. We have also explored the deformation evolution characteristics and spatial response mode of surrounding rock based on geological in situ monitoring data from construction sequences. Furthermore, we firstly proposed the concept and constructed a VDP curve suitable for rock mass with high integrity and few fissures or faults on the basis of theoretical analysis and in situ monitoring data. Our main conclusions are as follows:

(1) The in situ monitoring data and numerical simulations show that the deformation of surrounding rock increases in a "step shape" when layered excavation is adopted for large underground cavern construction. In rock mass with high integrity and few fissures or faults, the vertical spatial response of surrounding rock deformation is particularly clear

(2) In order to describe the vertical spatial response, we define its attenuation function $\lambda(x)$ of unloading deformation. According to the numerical simulation results, using regression fitting of the calculation results under different geological conditions and support methods, we obtain a consistent form of $\lambda(x)$. By combining the initial excavation unloading response strength $\Lambda_{0}$ obtained from in situ monitoring data with the attenuation function $\lambda(x)$ and the height of each excavation layer, we obtain the unloading response intensity $\Lambda$ of each excavation layer and can then construct the VDP curve

(3) The VDP curve is implemented to the Baihetan and Lianghekou Hydropower Stations in China. Based on a small amount of data obtained at the initial stage of excavation, the VDP curve of the monitoring point can be obtained by regression fitting with a L-M algorithm. A deformation warning system for surrounding rock can be established by constructing a VDP curve for each monitoring point in the cavern. The method for building such an early warning 
system is simple and can be mastered and applied by engineering field technicians

(4) In this paper, the vertical excavation are studied, but the role of follow-up support is not considered. In the future, based on the current VDP curve, the support factor is introduced to make the deformation control more effective

\section{Data Availability}

The test data used to support the findings of this study are included within the article.

\section{Conflicts of Interest}

No conflict of interest exits in the submission of this manuscript.

\section{Acknowledgments}

The study is financially supported by the National Natural Science Foundation of China (grant number 51879284), the Fundamental Research Funds Project of China Institute of Water Resources and Hydropower Research (grant numbers GE0145B452016 and GE0145B822017), and the National Key R\&D Program of China fund (grant number 2017YFC1501202).

\section{References}

[1] S. R. Zheng, "Development and utilization of hydropower resourses in China: opportunity and challenges," Journal of Hydraulic Engineering, vol. S1, pp. 1-6, 2007.

[2] Y. X. Xiao, X. T. Feng, G. L. Feng, H. J. Liu, Q. Jiang, and S. L. Qiu, "Mechanism of evolution of stress-structure controlled collapse of surrounding rock in caverns: a case study from the Baihetan hydropower station in China," Tunnelling and Underground Space Technology, vol. 51, pp. 56-67, 2016.

[3] H. B. Li, X. G. Yang, X. B. Zhang, and J. W. Zhou, "Deformation and failure analyses of large underground caverns during construction of the Houziyan Hydropower Station, Southwest China," Engineering Failure Analysis, vol. 80, pp. 164-185, 2017.

[4] W. Y. Wang, Y. P. Cheng, H. F. Wang et al., "Fracture failure analysis of hard-thick sandstone roof and its controlling effect on gas emission in underground ultra-thick coal extraction," Engineering Failure Analysis, vol. 54, pp. 150-162, 2015.

[5] A. Q. Wu, P. Xu, C. M. Xu, and Y. Yu, "Reseaches on stability for surrounding rock masses of underground powerhouse in the Three Gorges Project," Chinese Journal of Rock Mechanics and Engineering, vol. 20, no. 5, pp. 690-695, 2001.

[6] P. Y. Su, D. K. Wang, P. You et al., "Displacement characteristics analysis of surrounding rock in underground powerhouse chambers at Pubugou hydropower station during construction," Chinese Journal of Rock Mechanics and Engineering, vol. 30, Supplement 1, pp. 3032-3042, 2011.

[7] Q. Yang, H. X. She, Z. G. Li, W. B. Ou, and J. H. Zhang, "Monitoring feedback and forecast analysis on excavation of the upper part of Houziyan underground powerhouse," Chinese
Journal of Underground Space and Engineering, vol. 12, no. 3, pp. 738-746, 2016.

[8] J. H. Li, W. F. Wu, and J. C. Li, "Control and monitoring of rock mass engineering of super large underground powerhouse cavern groups at Xiluodu hydropower station," Chinese Journal of Rock Mechanics and Engineering, vol. 32, no. 1, pp. 8-14, 2013.

[9] H. B. Li, M. C. Liu, W. B. Xing, S. Shao, and J. W. Zhou, "Failure mechanisms and evolution assessment of the excavation damaged zones in a large-scale and deeply buried underground powerhouse," Rock Mechanics and Rock Engineering, vol. 50, no. 7, pp. 1883-1900, 2017.

[10] J. H. Yang, Z. N. Wu, C. Yao, and S. H. Jiang, "Characteristics and PPV thresholds of rock damages under underground blasting excavation," Journal of Vibration and Shock, vol. 38, no. 2, pp. 131-139, 2019.

[11] Y. P. Zhang, L. P. Li, P. He, and C. S. Qin, "Gaussian process regression prediction model for the big deformation of the tunnel rock and its application," Science Technology and Engineering, vol. 18, no. 1, pp. 122-127, 2018.

[12] D. Hu, X. L. Huang, and J. He, "Prediction of deformation of tunnel surrounding rock based on improved grey theory model," Highway Engineering, vol. 42, no. 5, pp. 72-75, 2017.

[13] X. R. Wang and Y. H. Wang, "Intelligent direct analysis of physical and mechanical parameters of tunnel surrounding rock based on adaptive immunity algorithm and BP neural network," Journal of Pharmaceutical Analysis, vol. 21, no. 1, pp. 22-30, 2009.

[14] B. Z. Yao, C. Y. Yang, J. B. Yao, and J. Sun, "Tunnel surrounding rock displacement prediction using support vector machine," International Journal of Computational Intelligence Systems, vol. 3, no. 6, pp. 843-852, 2010.

[15] M. Wen, D. L. Zhang, Q. Fang, J. Qi, H. C. Huang, and W. B. Chen, "Research on nonlinear auto regressive time series method for predicting deformation of surrounding rock in tunnel," Journal of Beijing Jiaotong University, vol. 41, no. 4, pp. 1-7, 2017.

[16] J. B. Wei, J. H. Deng, D. K. Wang, D. W. Cai, and J. Z. Hu, "Characterization of deformation and fracture for rock mass in underground powerhouse of jinping I hydropower station," Chinese Journal of Rock Mechanics and Engineering, vol. 29, no. 6, pp. 1198-1205, 2010.

[17] P. J. Yuan, J. H. Sun, Z. Z. Liu, and Z. H. Zhu, "Monitoring analysis for rock stability of underground main power house in xiangjiaba hydropower station," Chinese Journal of Rock Mechanics and Engineering, vol. 29, no. 6, pp. 1140-1148, 2010.

[18] Y. Zhang, P. X. Xiao, X. L. Ding et al., "Study of deformation and failure characteristics for surrounding rocks of underground powerhouse caverns under high geostress condition and countermeasures," Chinese Journal of Rock Mechanics and Engineering, vol. 31, no. 2, pp. 228-244, 2012.

[19] D. K. Wang, D. W. Cai, Y. F. Dong, and X. Sun, “Analysis of deformation characteristics of surrounding rock of underground powerhouse of Houziyan hydropower station and its control," Yangtze River, vol. 45, no. 8, pp. 66-69, 2014.

[20] T. Unlu and H. Gercek, "Effect of Poisson's ratio on the normalized radial displacements occurring around the face of a circular tunnel," Tunnelling and Underground Space Technology, vol. 18, no. 5, pp. 547-553, 2003.

[21] N. Vlanchopoulos and M. S. Diederichs, "Improved longitudinal displacement profiles for convergence confinement 
analysis of deep tunnels," Rock Mechanics and Rock Engineering, vol. 42, no. 2, pp. 131-146, 2009.

[22] L. Cui, J. J. Zheng, C. X. Miao, and Y. K. Dong, "Coupling analysis of longitudinal deformation profile and ground reaction curve," Chinese Journal of Geotechnical Engineering, vol. 36, no. 4, pp. 707-715, 2014.

[23] S. C. Wu, X. J. Geng, Y. T. Gao, G. J. Zhao, J. Li, and Q. Yan, “A study of the longitudinal deformation of tunnels based on the generalized Hoek-Brown failure criterion," Rock and Soil Mechanics, vol. 36, no. 4, pp. 946-952, 2015.

[24] S. Hibino and M. Motojima, "Rock mass behavior during large-scale cavern excavation," International Journal of Rock Mechanics and Mining Sciences and Geomechanics Abstracts, vol. 31, no. 4, pp. 631-651, 1993.

[25] W. S. Zhu, A. H. Sun, W. T. Wang, and S. C. Li, "Study on prediction of high wall displacement and stability judging method of surrounding rock for large cavern groups," Chinese Journal of Rock Mechanics and Engineering, vol. 26, no. 10, pp. 17291736, 2007.

[26] X. Q. Yang, X. Liu, and Z. Li, "Multimodel approach to robust identification of multiple-input single-output nonlinear timedelay systems," IEEE Transactions on Industrial Informaticshinese, vol. 16, no. 4, pp. 2413-2422, 2020.

[27] X. Q. Yang, Y. Shen, and O. Kaynak, "Robust identification of LPV time-delay system with randomly missing measurements," IEEE Transactions on Systems, Man, and Cybernetics: Systems, vol. 48, no. 12, pp. 2198-2208, 2018.

[28] X. Q. Yang, X. Liu, and Y. Shen, "Robust identification of nonlinear systems with missing observations: the case of statespace model structure," IEEE Transactions on Industrial Informatics, vol. 15, no. 5, pp. 2763-2774, 2019.

[29] X. Q. Yang and S. Yin, "Variational Bayesian inference for FIR models with randomly missing measurements," IEEE Transactions on Industrial Informatics, vol. 64, no. 5, pp. 1-9, 2016.

[30] G. L. Hu, Z. F. Zhou, J. Z. Cao, and H. Huang, "Non-linear calibration optimisation based on the Levenberg-Marquardt algorithm," IET Image Processing, vol. 14, no. 7, pp. 14021414, 2020.

[31] Y. G. Zhang, J. Tang, R. P. Liao, M. F. Zhang, W. X. M. ZhangY, and Z. Y. Su, "Application of an enhanced BP neural network model with water cycle algorithm on landslide prediction," Stochastic Environmental Research and Risk Assessment, 2020.

[32] Y. G. Zhang, J. Tang, Z. Y. He, J. K. Tan, and C. Li, “A novel displacement prediction method using gated recurrent unit model with time series analysis in the Erdaohe landslide," Natural Hazards, vol. 105, pp. 783-813, 2021.

[33] Y. G. Zhang and L. N. Yang, "A novel dynamic predictive method of water inrush from coal floor based on gated recurrent unit model," Natural Hazards, vol. 105, pp. 2027-2043, 2020.

[34] Y. G. Zhang, Z. Zhang, and S. Xue, "Stability analysis of a typical landslide mass in the Three Gorges Reservoir under varying reservoir water levels," Environmental Earth Sciences, vol. 79, no. 1, 2020.

[35] Y. G. Zhang, S. Y. Zhu, J. K. Tan, L. D. Li, and X. J. Yin, “The influence of water level fluctuation on the stability of landslide in the Three Gorges Reservoir," Arabian Journal of Geosciences, vol. 13, no. 17, p. 845, 2020.

[36] Y. G. Zhang, S. Y. Zhu, W. Q. Zhang, and H. Liu, "Analysis of deformation characteristics and stability mechanisms of typi- cal landslide mass based on the field monitoring in the Three Gorges Reservoir, China," Journal of Earth System Science, vol. 128, no. 1, 2019.

[37] B. Gong, Y. J. Jiang, P. Yan, and S. Zhang, "Discrete element numerical simulation of mechanical properties of methane hydrate-bearing specimen considering deposit angles," Journal of Natural Gas Science and Engineering, vol. 76, article 103182, 2020.

[38] B. Gong, Y. J. Jiang, and L. J. Chen, "Feasibility investigation of the mechanical behavior of methane hydrate- bearing specimens using the multiple failure method," Journal of Natural Gas Science and Engineering, vol. 69, article 102915, 2019. 